\title{
Cross-Talk between PPARs and the Partners of RXR: A Molecular Perspective
}

\author{
Lap Shu Alan Chan ${ }^{1,2,3}$ and Richard A. Wells $s^{1,2,3,4}$ \\ ${ }^{1}$ Department of Medical Biophysics, University of Toronto, Toronto, ON, Canada M5G 2M9 \\ ${ }^{2}$ Discipline of Molecular and Cellular Biology, J. Douglas Crashley Myelodysplastic Syndrome Laboratory, \\ Sunnybrook Research Institute, 2075 Bayview Avenue, T2-058, Toronto, ON, Canada M4N 3M5 \\ ${ }^{3}$ Department of Medical Oncology, Crashley Myelodysplastic Syndromes Research Laboratory, Odette Cancer Centre, \\ Sunnybrook Health Sciences Centre, Toronto, ON, Canada M4N 3M5 \\ ${ }^{4}$ Department of Medicine, University of Toronto, Toronto, ON, Canada M4G 2C4
}

Correspondence should be addressed to Richard A. Wells, rwells@sri.utoronto.ca

Received 2 September 2009; Accepted 7 September 2009

Recommended by Xing-Ming Shi

The PPARs are integral parts of the RXR-dependent signaling networks. Many other nuclear receptor subfamily 1 members also require RXR as their obligatory heterodimerization partner and they are often co-expressed in any given tissue. Therefore, the PPARs often complete with other RXR-dependent nuclear receptors and this competition has important biological implications. Thorough understanding of this cross-talk at the molecular level is crucial to determine the detailed functional roles of the PPARs. At the level of DNA binding, most RXR heterodimers bind selectively to the well-known "DR1 to 5" DNA response elements. As a result, many heterodimers share the same DR element and must complete with each other for DNA binding. At the level of heterodimerization, the partners of RXR share the same RXR dimerization interface. As a result, individual nuclear receptors must complete with each other for RXR to form functional heterodimers. Cross-talk through DNA binding and RXR heterodimerization present challenges to the study of these nuclear receptors that cannot be adequately addressed by current experimental approaches. Novel tools, such as engineered nuclear receptors with altered dimerization properties, are currently being developed. These tools will enable future studies to dissect specific RXR heterodimers and their signaling pathways.

Copyright (C) 2009 L. S. A. Chan and R. A. Wells. This is an open access article distributed under the Creative Commons Attribution License, which permits unrestricted use, distribution, and reproduction in any medium, provided the original work is properly cited.

\section{Introduction}

The PPARs are one of the most studied RXR heterodimerization partners. Over 1000 papers have been published on the PPARs since their cloning in 1990 [1]. Although some evidence suggests that the PPARs can form homodimers and bind to DNA response elements such as the Pal3 motif [2], it is widely accepted that the PPARs must heterodimerize with RXR to carry out most of their functions. Therefore, like other RXR's partners, the PPARs are integral parts of the RXR-dependent signaling network-RXR is also the obligatory heterodimerization partner of at least twenty mammalian nuclear receptors (NRs) [3-10]. Since studies in mouse have shown that multiple RXR's partners are often coexpressed in any given tissue [11-16] (also see the Nuclear Receptor Signaling Atlas (NURSA) [17]), it appears that cross-talk between these partners is a common phenomenon. Cross-talk between these partners is complex and presents a unique challenge to researchers who are trying to understand the function of individual NR.

This paper will focus on the basis of the cross-talks between RXR's partners from a molecular biology perspective, where these NRs compete against each other for DNA binding and RXR heterodimerization. In addition, this paper will discuss the challenges faced by investigators using current experimental approaches to dissect and understand the functional role of individual partners of RXR. 


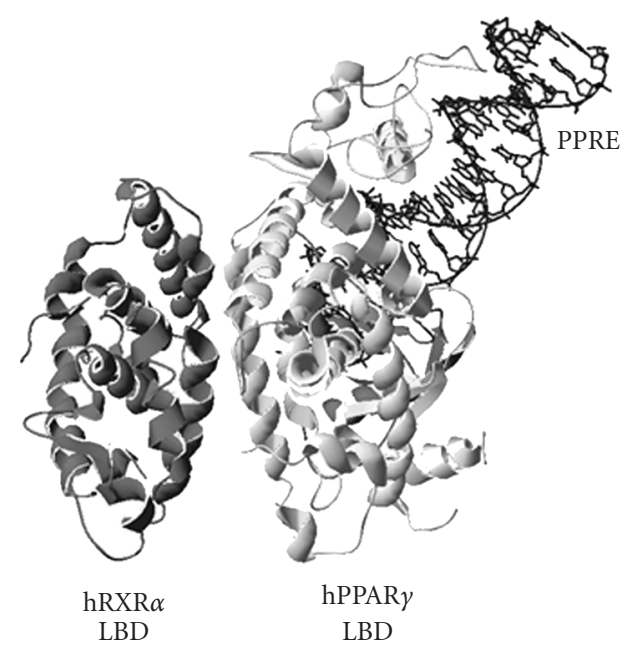

(a)

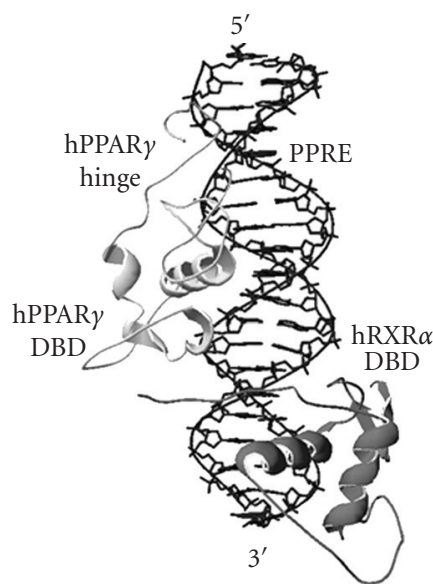

(b)

FIgure 1: (a) Ribbon drawing of the human RXR $\alpha$ /human PPAR $\gamma$ heterodimer on PPRE (PBD 3E00). (b) Ribbon drawing of the heterodimer/DNA complex showing only the PPRE and the DBDs of RXR $\alpha$ and PPAR $\gamma$. The RXR and PPAR monomers are colored in dark and light grey, respectively. The PPRE is colored in black; the $5^{\prime}$ and $3^{\prime}$ ends are also labeled.

\section{How Do RXR Heterodimers Bind to Their DNA Response Elements?}

Most RXR/partner heterodimers recognize and bind to direct repeat (DR) DNA sequences as their response element [1823]. The consensus DR sequence consists of two direct repeat half-sites separated by a number of nucleotides ( $5^{\prime}$-AGGTCA $n(x)$ AGGTCA-3'). A DR separated by a single nucleotide is referred to as DNA response element direct repeat 1 (DR1). In addition, the sequence of the actual 5'-AGGTCA$3^{\prime}$ half-site varies among different response elements. The $\mathrm{RXR} \alpha / \operatorname{PPAR} \gamma$ heterodimer preferentially binds to the DR1 PPAR response element (PPRE) [24], and the crystal structure of this heterodimer/DNA complex is recently reported (Figure 1) [25]. During DNA binding, the heterodimer is arranged such that the DNA binding domain (DBD) from each monomer occupies one $5^{\prime}$-AGGTCA-3' half-site. Most heterodimers are selective toward DR sequences with one to five nucleotides spacing (i.e., DR1 to DR5). At the molecular level, addition or subtraction of a single base pair between the half-sites imposes a separation of $3.4 \AA$ and a rotation of $36^{\circ}$ between the two half-sites [19]. Since a DBD is only slightly longer than one half-site, the structural conformations required for the heterodimers vary greatly for different DRs. Heterodimerization of the DBDs on their correct DR elements helps define the structural conformation of the heterodimer, which in turn stabilizes the protein/DNA complex. It is also worth noting that the RXR DBD is flexible and undergoes structural changes to accommodate the DBDs from different partners.

There are two additional consequences to these DNA binding properties. First, unlike the inverted repeat DNA sequence used by other NRs, the DR sequence is asymmetrical and can only be read correctly from one direction [26-28]. This restricts the protein complex to bind to the DNA in only one orientation, in contrast to inverted repeats
TABLE 1: DR element binding properties of RXR homodimers and heterodimers.

\begin{tabular}{ll}
\hline DR element & RXR homo/heterodimer \\
\hline DR1 & RXR- RXR, RAR, PPAR, COUP, HNF4 \\
DR2 & RXR-PPAR, RAR \\
DR3 & RXR-VDR \\
DR4 & RXR-TR, LXR, CAR \\
DR5 & RXR-RAR, NGFI-B \\
\hline
\end{tabular}

or everted repeats, which can interact with their cognate NR complex in both $5^{\prime}$ and $3^{\prime}$ orientations. Consequently, the protein complex exerts its effect in a unidirectional manner. Second, unlike homodimers, heterodimers can bind to response elements with RXR occupying either the $5^{\prime}$ upstream or $3^{\prime}$ downstream half-site [29-32]. This difference in polarity effectively doubles the number of possible RXR/partner heterodimer combinations, even though not all combinations are capable of DNA binding. In addition, different RXR polarity can result in completely different gene regulatory responses. For instance, although the RXRRAR heterodimer binds to both DR1 and DR5, the RXR monomer occupies the $3^{\prime}$ half-site of DR1 and the $5^{\prime}$ halfsite for DR5 [30]. This allows ligand-dependent activation for RXR-RAR heterodimer on DR5, but not on DR1. Hence, different genes can be regulated in different manner by a given heterodimer and ligand. The crystal structure of $\operatorname{RXR} \alpha / \operatorname{PPAR} \gamma$ heterodimer on the PPRE reveals that PPAR $\gamma$ resides upstream of $\operatorname{RXR} \alpha$, resembling the organization of RXR/RAR on DR1 [25] (Figure 1). However, it is unclear whether $\operatorname{PPAR} \gamma$ can also reside downstream of $\operatorname{RXR} \alpha$ and exert different activation properties.

Since there are more than forty heterodimer combinations and only five DR response elements, many heterodimers share the same DR element (Table 1) [19]. 


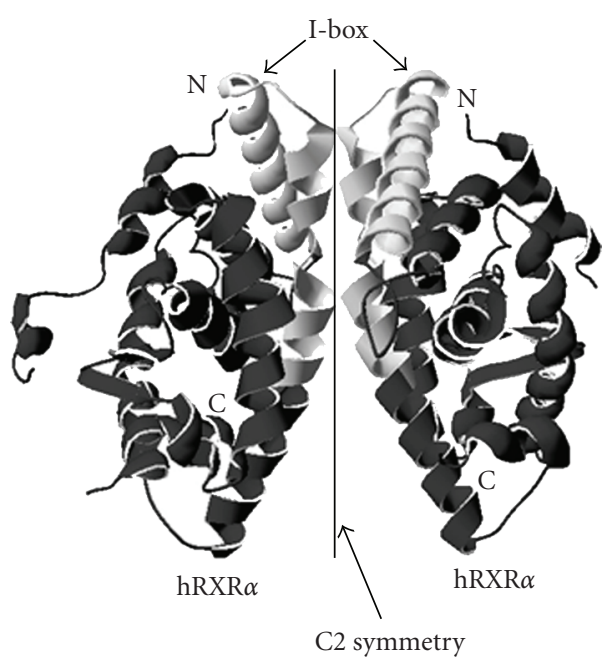

(a)

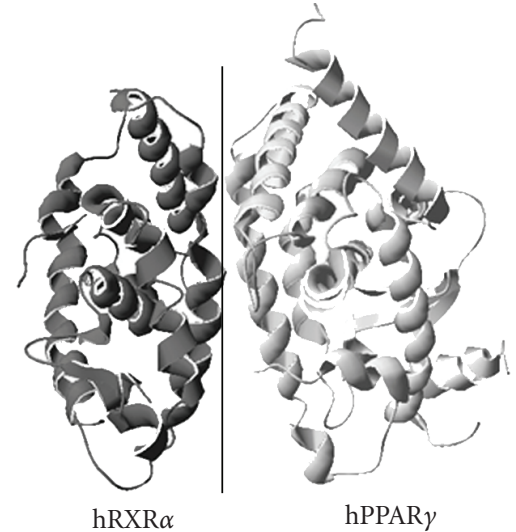

(b)

FIgURe 2: (a) Ribbon drawing of the human RXR $\alpha$ LBD homodimer (PBD 1MZN). The RXR monomers are colored in black. The N and $\mathrm{C}$ termini are labeled "N" and " $\mathrm{C}$ ", respectively. Rotation of $180^{\circ}$ on the Z-axis of the homodimer results in a geometry equivalent of the starting geometry (i.e., C2 symmetry). The I-boxes are colored in light grey. (b) Ribbon drawing of the hRXR $\alpha /$ hPPAR $\gamma$ LBD heterodimers (PDB 3E00, also see Figure 1). The RXR and PPAR monomers are colored in dark and light grey, respectively.

This implies that different heterodimers must compete for DNA binding. A well-known example is that the RXR homodimer and several other RXR heterodimers can recognize and bind to the DR1 element [29]. Subsequently, crosstalk becomes possible among different heterodimers and the signaling pathways they represent. Several mechanisms exist to control the relative affinity of these dimers to DR1 [33]. First, the expression level of NRs varies among different cell types; thus, protein abundance may determine DNA binding [11]. Second, the precise sequence of the DR element influences the binding specificity of different dimers. For instance, the PPREs have a well conserved AAACT extension sequence located upstream of the DR site [34]. The crystal structure of RXR $\alpha / \operatorname{PPAR} \gamma$ heterodimer revealed that the hinge region of $\operatorname{PPAR} \gamma$ can recognize this AAACT element and allow specific PPREs binding [25]. Nevertheless, the specificity of RXR/PPAR heterodimer to PPRE does not necessarily preclude DNA binding by other RXR heterodimers that also recognize the DR1 element.

\section{How Do RXR and Its Partners Form Heterodimers?}

Although RXR and its partners may perform certain functions as monomers or homodimers, the heterodimers are responsible for most gene regulatory activities. Therefore, it is reasonable to regard the heterodimer as the basic functional unit of the signaling network, rather than viewing RXR and its partner monomer as separate units. Numerous studies have been conducted to investigate the heterodimerization properties of RXR and its partners using X-ray crystallography and mutational analysis of the amino acid sequence. Although both the DBD and the ligand binding domain (LBD) are involved in dimerization, the LBD is more important due to its much larger and stronger dimerization interface $[35,36]$. Therefore, studies on RXR/partner heterodimerization have mainly focused on the LBD.

3.1. The Structure of RXR Homo/Heterodimer. The RXR LBD homodimer (Figure 2(a)) was the first RXR dimer to be resolved by X-ray crystallography [36]. Each RXR monomer consists of twelve $\alpha$-helices (H1 to H12) and two short $\beta$-strands (s1 and s2), which are organized in three layers to form an antiparallel " $\alpha$-helical sandwich" [37]. The homodimer has twofold symmetry and forms a rotationally symmetric dimer. The dimer interface consists of amino acid residues that are arranged as a hydrophobic cluster surrounded by charged and polar residues. These residues interact with each other to stabilize the homodimer and therefore are essential for dimerization. The structural arrangement of the PPAR LBD resembles that of the RXR LBD, except the PPAR LBD has one extra $\alpha$-helice and two extra $\beta$ strands [38]. The crystal structures of several RXR/partner LBD heterodimers have been resolved since the publication of the RXR LBD homodimer, including RXR/RAR $[39,40]$, RXR/CAR [41, 42], RXR/LXR [43, 44], and RXR/PPAR [25, 45-47]. These heterodimers share the same global structure with the RXR LBD homodimer. Nevertheless, individual heterodimers have specific configurations, which differ from the RXR homodimer prototype. These differences include deviation of a monomer from the symmetry axis, the exact area that the monomers contribute to the dimer interface, and the rearrangement of interactions between amino acid residues from the monomers. For instance, the monomers of the RXR $\alpha /$ PPAR $\gamma$ LBD heterodimer (Figure 2(b)) [25] deviate about $10^{\circ}$ from the $\mathrm{C} 2$ symmetry, which leads to increased surface contact area between the monomers and enhances the stability of the heterodimer [45]. 
Since each heterodimer possesses different heterodimerization interface, it is reasonable to conjecture that some partners can form more stable heterodimers with RXR than can others, even though the relative stability of each heterodimer is yet to be fully established. It has been suggested that the quantity of RXR available for heterodimerization is limited and under strict control [48, 49]. As a result, cross-talk between RXR's partners can be achieved via RXR sequestration. For instance, the presence of excess LXR or its ligands reduces DNA binding of PPAR $\alpha / \operatorname{RXR} \alpha$ to PPRE [50], which inhibits PPAR signaling and suppresses transcription of lipid degradation genes. Conversely, excess of PPAR $\alpha$ and its ligands suppresses the sterol regulatory elementbinding protein-1c promoter that contains two LXR response elements [51]. This inhibition can be relieved by the addition of $\operatorname{RXR} \alpha$, suggesting that competition for and sequestration of RXR is a contributor to cross-talk between the LXR and PPAR signaling pathways. Other examples of cross-talks between RXR's partners include PPAR with COUP-TF [52], TR with LXR [53], TR with VDR [54], and multiple partners (CAR, PXR, LXR, FXR, and PPAR) on the expression of P450 enzymes [55].

\subsection{Amino Acid Residues that Are Important in Dimerization.} The dimer interface holds the key to dimerization, and amino acid residues within this interface are especially important. Early studies showed that deletion of the RXR LBD from amino acid position 443 to the C-terminal end does not disrupt dimerization [56], while additional deletion to position 433 disrupts RXR homodimerization but not heterodimerization with other NRs. Further deletion to position 413 abolishes all dimerization activities. These observations suggested that a short region of RXR 413443 is required for dimerization, and the region 413-433 is particularly important to heterodimerization. Subsequent analysis by the Evans' group redefined the heterodimerization region as 387-429 and termed this region the "I-box" [57] (Figures 2 and 3). As observed in the crystal structure, the I-box lies within helices H9-H10, which is at the center of the dimer interface. RXR and all of its known partners possess the I-box, and a number of highly conserved amino acid residues are found in this region. Interestingly, RAR acquires the heterodimerization properties of RXR when its I-box is replaced by that of the RXR, and vice versa [57].

Mutational analysis of RXR homo- and heterodimerization has also utilized amino acid mutations through site directed mutagenesis. The results indicated that combination of mutations at the I-box disrupt dimerization, presumably through steric hindrance or charge confliction within the dimer interface. For instance, the Pfahl's group has reported that simultaneous mutations of L418R, L419S, and L422Q can completely abolish RXR homo- and heterodimerization [56]. In addition, other mutations can alter heterodimerization of RXR with certain partners. These mutations include RXR A416D or R421L, which specifically disrupt the formation of the RXR/TR heterodimer, and RXR A416K, which disrupts RXR/RAR and RXR/TR [58]. Likewise, the I-box of the partner of RXR is equally vital to heterodimerization, such as VDR K382E (equivalent to human RXR $\alpha$ K417) cannot form heterodimers with RXR [59]. The I-box may also hold the key that determine RXR homo- and heterodimerization. The Gronemeyer's group has reported that a RXR mutant (Y402A) is able to provide additional stabilization to the RXR homodimer interface, making the RXR mutant unavailable for heterodimerization [35]. Overall, these studies identify the I-box as a crucial element for RXR heterodimerization, and mutations at this region can alter heterodimerization properties.

\section{Studies on the RXR-Dependent Signaling Network and Its Individual Pathways}

A number of experimental approaches have been employed to study the function of RXR and its partners, including targeted gene disruption, naturally occurring NR mutants, and heterodimer specific ligand stimulation. Studies using these approaches have contributed greatly to the understanding of the RXR dependent signaling network. However, there are limitations and it remains difficult to address the functional roles of individual heterodimers in isolation.

4.1. Targeted Gene Disruption. Gene knockout models have been extensively used to characterize the physiological role of RXRs. RXR $\alpha$ knockout (-/-) in mouse is embryonic lethal in mid-gestation because of a noncell autonomous defect in the development of the ventricular myocardium $[60,61]$. It is possible to bypass the embryonic lethality using tissue specific conditional knockout [61]. Studies based on this system suggested that RXR $\alpha$ has an essential role in multiple pathways including glutathione homeostasis and detoxification of xenobiotics [62], the lifespan and regenerative capacity of hepatocytes [63], proliferation and differentiation of epidermal keratinocytes $[64,65]$, and development of prostatic intraepithelial neoplasia [66]. Knockout of PPAR $\gamma$ in mouse has established its involvement in the development placental, cardiac, and adipose tissue [67-69], while RARs are involved in spermatogenesis and fetal development $[70,71]$. Observations from these gene disruption models have helped to establish the physiological roles of RXR and its partners. However, these models cannot clearly define the exact functions of individual heterodimers because of the unique relationship between RXR and its partners. First, genes from a particular signaling pathway can be coregulated by one or more pathways. For instance, disruption of one RAR isoforms is often compensated by the other two RAR isoforms [70, 71]. This implies that the remaining intact pathways can mask the effect of the knockout by maintaining certain gene regulatory activities normally handled by the absent partner. Second, the absence of a partner through targeted gene disruption increases the availability of RXR and cofactors. Consequently, these excess proteins can enhance the activities of other intact heterodimers and their subsequent signaling pathways.

4.2. Heterodimer Specific Ligand Stimulation. Liganddependent activities of RXR heterodimers are of major 


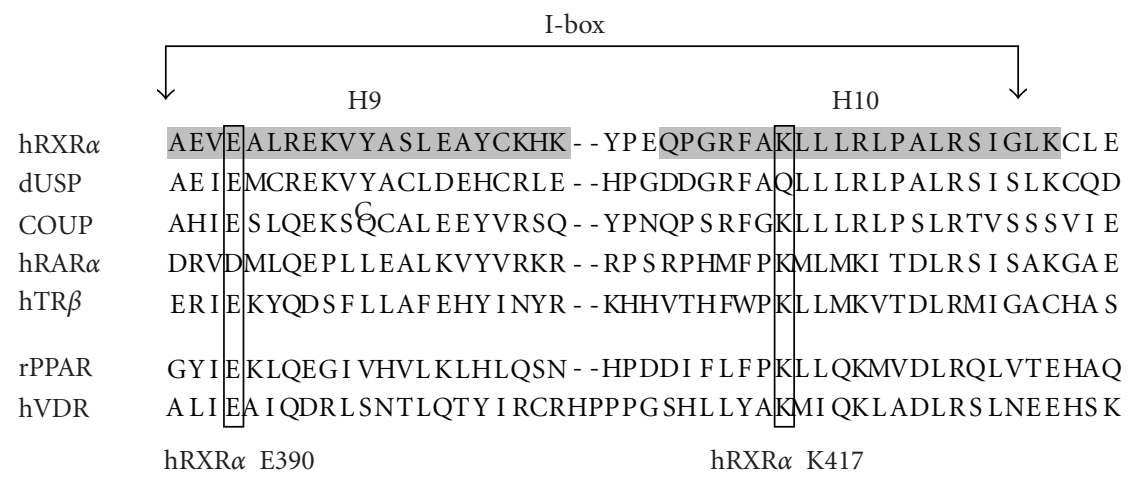

FIGURE 3: Amino acid sequences of the I-box region of RXR $\alpha$, USP, COUP, RAR $\alpha$, TR $\beta$, PPAR, and VDR. The I-box lies within Helix 9 (H9) and helix 10 (H10) (shaded) and has been shown to be essential to dimerization. The amino acid residues equivalent to hRXR $\alpha 390$ and K417 are also marked.

interest in NR research due to their physiological relevance and potential application in medicine. For instance, thiazolidinediones (TZDs) activate PPAR $\gamma$ in brown and white adipocyte, and induce the transcription of PGC-1 alpha. PGC-1 alpha is involved in the control of mitochondrial biogenesis and has been linked to insulin sensitization [72]. Other pharmacological compounds such as WY-14643[73], L-165041 [74], and GW-7845 [75] are specific ligands for $\alpha, \delta$, and $\gamma$ isoforms, respectively. Bisphenol diglycidyl ether (BADGE) [76] and LG100641 [77] are PPAR $\gamma$ selective antagonists, while nonsteroidal anti-inflammatory drugs (NSAIDs) can block PPAR $\delta$ specifically [78]. Nevertheless, a number of heterodimerspecific ligands exert effects independent of their receptor. For instance, PPAR $y$ specific ligands troglitazone and 15-deoxy-prostaglandin J2 inhibit growth of prostate and bladder carcinoma cell lines. However, this effect is not blocked by a PPAR $\gamma$ antagonist [79]. This observation leads to the conclusion that the particular growth inhibition effects of both agents are mediated through PPAR $\gamma$ independent mechanisms $[79,80]$. Receptor independent effects have also been reported for RAR ligands [81]. Hence, even though these effects may be essential to medical and pharmaceutical applications, they do not contribute to the RXR dependent signaling network and may create confusion in analyzing the functions of individual heterodimers. Furthermore, the use of ligands cannot address the functional role of apo-heterodimers, which binds to their respective response element even in the absence of ligand.

4.3. A New Approach to Dissect Individual RXR Signaling Pathway. The research of RXR dependent signaling networks requires the precise characterization of individual signaling pathways. However, current experimental approaches are insufficient to achieve this objective due to the unique properties of the signaling network. A novel experimental system consisting of engineered RXR and partners with controllable heterodimerization specificity would be helpful to complement the existing approaches and to circumvent their limitations. Our laboratory has created and tested an engineered RXR/PPAR heterodimer consist of mouse

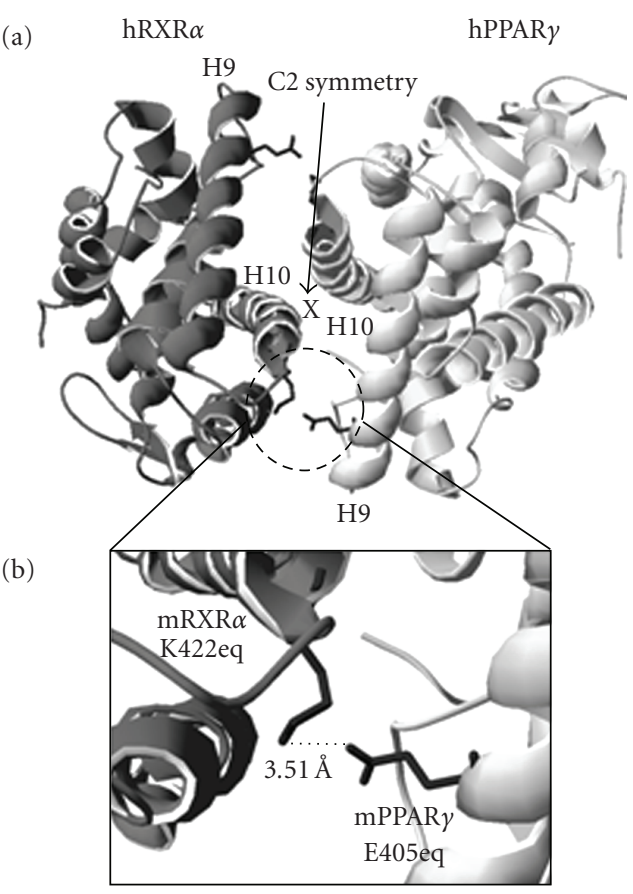

FIgURE 4: (a) Ribbon drawing of hRXR $\alpha / \mathrm{hPPAR} \gamma \mathrm{LBD}$ heterodimer (PDB 3E00, also see Figure 2). (b) The detail view of the equivalent amino acid sidechains of mouse RXR $\alpha$ K 422 and mouse PPAR $\gamma$ E405. The shortest distance between the negative (side chain carboxyl group of E405) and positive (side chain amino group of K422) charges is also displayed.

RXR $\alpha$ K422E and mouse PPAR $\gamma$ E405K mutants [82]. The creation of these mutants is based on the proposed saltbridge between RXR $\alpha$ K422 and PPAR $\gamma$ E405 (Figure 4). In addition, PPAR $\gamma$ E405 and RXR $\alpha$ K422 correspond to human RXR $\alpha$ E390 and K417, which are highly conserved among RXR and its partners in mammalian species (Figure 3 ). Since this salt-bridge is located within the heterodimer interface, we postulate that this salt-bridge may have a role in heterodimerization. We also hypothesized that reversing the polarity of the side chains of these amino acids may alter 
TABLE 2: Altered heterodimerization properties of the RXR and PPAR charge-reversal mutants.

\begin{tabular}{lcc}
\hline RXR & PPAR & Heterodimer? \\
\hline Wide-type & Wide-type & YES \\
Wide-type & E405K & YES \\
K422E & Wide-type & NO \\
K422E & E405K & YES \\
\hline
\end{tabular}

heterodimerization specificity but the salt-bridge will be kept intact. Indeed, our observations suggest that the mutant pair is able to form a heterodimer. Although PPAR $\gamma$ E405K can form a heterodimer with wild-type $\operatorname{RXR} \alpha, \operatorname{RXR} \alpha \mathrm{K} 422 \mathrm{E}$ is not able to heterodimerize with wild-type PPAR $\gamma$ (Table 2). In addition, ligand response of the PPAR $\gamma$ E405K mutant is comparable to that of the wild-type PPAR $\gamma$, suggesting that the general structure of this mutant is preserved. The restricted heterodimerization capacity of the $\mathrm{RXR} \alpha \mathrm{K} 422 \mathrm{E}$ mutant is especially exciting, since the salt-bridge between RXR $\alpha$ K422 and PPAR $\gamma$ E405 (Figure 4(b)) is predicted to exist in other RXR's partners based on the crystal structures of the LBD heterodimers (RXR/RAR [39, 40], RXR/CAR [41, 42], RXR/LXR [43, 44], and RXR/PPAR [45-47]). We are currently conducting experiments to determine if the restriction on heterodimerization of $\mathrm{RXR} \alpha \mathrm{K} 422 \mathrm{E}$ is also applicable to other NR partners, and if mutants of these partners (equivalent to PPAR $\gamma$ E405K) can restore heterodimerization with $\mathrm{RXR} \alpha \mathrm{K} 422 \mathrm{E}$. If true, our approach will permit rescue, in the context of RXR knockout, of specific NR pathway either by knock-in or by in vitro delivery of dimerization restricted NR pairs. Expression of RXR $\alpha$ K422E and PPAR $\gamma$ E405K mutants in RXR $\alpha-/-$ cells could, for instance, be used to restore specifically the functions mediated by $\operatorname{RXR} \alpha / \operatorname{PPAR} \gamma$ heterodimer, thus identifying the contribution of this particular heterodimer to the whole phenotype. Hence, it maybe possible to dissect the RXRdependent signaling pathway in a precise manner using dimerization-restricted NR pairs.

In summary, more than twenty RXR heterodimers share only five common DNA response elements. Although some of these DNA response elements have features that favor binding by specific heterodimer, direct competition for DNA binding is a common phenomenon for these heterodimers. Competition for RXR among the partners of RXR is also intense due to the expression of multiple NRs in the same cell and the limited availability of RXR. There is evidence suggesting that the relative expression level of different NRs and RXR dictates the activity of individual NR pathways. Hence, direct competition for DNA binding and heterodimerization has significant roles in the crosstalk between PPARs and other RXR's partners. These unique properties present challenges to the study of these partners. A novel experimental approach is currently being developed to alter the dimerization properties of selected heterodimers, which will allow future studies to dissect a specific RXR heterodimer and its signaling pathway from the rest of the RXR-dependent signaling network.

\section{References}

[1] I. Issemann and S. Green, "Activation of a member of the steroid hormone receptor superfamily by peroxisome proliferators," Nature, vol. 347, no. 6294, pp. 645-650, 1990.

[2] M. Okuno, E. Arimoto, Y. Ikenobu, T. Nishihara, and M. Imagawa, "Dual DNA-binding specificity of peroxisomeproliferator-activated receptor $\gamma$ controlled by heterodimer formation with retinoid X receptor $\gamma$," Biochemical Journal, vol. 353, no. 2, pp. 193-198, 2001.

[3] S. Y. Tsai and M.-J. Tsai, "Chick ovalbumin upstream promoter-transcription factors (COUP-TFs): coming of age," Endocrine Reviews, vol. 18, no. 2, pp. 229-240, 1997.

[4] D. J. Mangelsdorf and R. M. Evans, "The RXR heterodimers and orphan receptors," Cell, vol. 83, no. 6, pp. 841-850, 1995.

[5] V. Giguere, "Orphan nuclear receptors: from gene to function," Endocrine Reviews, vol. 20, no. 5, pp. 689-725, 1999.

[6] A. A. Bogan, Q. Dallas-Yang, M. D. Ruse Jr., et al., "Analysis of protein dimerization and ligand binding of orphan receptor HNF4 $\alpha$, Journal of Molecular Biology, vol. 302, no. 4, pp. 831851, 2000.

[7] C.-H. Lee, C. Chinpaisal, and L.-N. Wei, "A novel nuclear receptor heterodimerization pathway mediated by orphan receptors TR2 and TR4," Journal of Biological Chemistry, vol. 273, no. 39, pp. 25209-25215, 1998.

[8] R. H. Zetterstrom, L. Solomin, T. Mitsiadis, L. Olson, and T. Perlmann, "Retinoid X receptor heterodimerization and developmental expression distinguish the orphan nuclear receptors NGFI-B, Nurr1, and Nor1," Molecular Endocrinology, vol. 10, no. 12, pp. 1656-1666, 1996.

[9] P. L. Hallenbeck, M. S. Marks, R. E. Lippoldt, K. Ozato, and V. M. Nikodem, "Heterodimerization of thyroid hormone (TH) receptor with $\mathrm{H}-2 \mathrm{RIIBP}(\mathrm{RXR} \beta)$ enhances DNA binding and TH-dependent transcriptional activation," Proceedings of the National Academy of Sciences of the United States of America, vol. 89, no. 12, pp. 5572-5576, 1992.

[10] W. Seol, H.-S. Choi, and D. D. Moore, "Isolation of proteins that interact specifically with the retinoid $\mathrm{X}$ receptor: two novel orphan receptors," Molecular Endocrinology, vol. 9, no. 1, pp. 72-85, 1995.

[11] M. Nishimura, S. Naito, and T. Yokoi, "Tissue-specific mRNA expression profiles of human nuclear receptor subfamilies," Drug Metabolism and Pharmacokinetics, vol. 19, no. 2, pp. 135149, 2004.

[12] P. Dolle, "Developmental expression of retinoic acid receptors (RARs)," Nuclear Receptor Signaling, vol. 7, article e006, 2009.

[13] L. Michalik, B. Desvergne, C. Dreyer, M. Gavillet, R. N. Laurini, and W. Wahli, "PPAR expression and function during vertebrate development," International Journal of Developmental Biology, vol. 46, no. 1, pp. 105-114, 2002.

[14] D. Forrest, M. Sjoberg, and B. Vennstrom, "Contrasting developmental and tissue-specific expression of $\alpha$ and $\beta$ thyroid hormone receptor genes," EMBO Journal, vol. 9, no. 5, pp. 1519-1528, 1990.

[15] D. K. Panda, S. A. Kawas, M. F. Seldin, G. N. Hendy, and D. Goltzman, "25-Hydroxyvitamin D $1 \alpha$-hydroxylase: structure of the mouse gene, chromosomal assignment, and developmental expression," Journal of Bone and Mineral Research, vol. 16, no. 1, pp. 46-56, 2001.

[16] L. J. Jonk, M. E. de Jonge, C. E. Pals, et al., "Cloning and expression during development of three murine members of the COUP family of nuclear orphan receptors," Mechanisms of Development, vol. 47, no. 1, pp. 81-97, 1994. 
[17] N. J. McKenna, A. J. Cooney, F. J. Demayo, et al., "Minireview: evolution of NURSA, the nuclear receptor signaling atlas," Molecular Endocrinology, vol. 23, no. 6, pp. 740-746, 2009.

[18] K. Umesono, K. K. Murakami, C. C. Thompson, and R. M. Evans, "Direct repeats as selective response elements for the thyroid hormone, retinoic acid, and vitamin D3 receptors," Cell, vol. 65, no. 7, pp. 1255-1266, 1991.

[19] F. Rastinejad, "Retinoid X receptor and its partners in the nuclear receptor family," Current Opinion in Structural Biology, vol. 11, no. 1, pp. 33-38, 2001.

[20] B. M. Forman and R. M. Evans, "Nuclear hormone receptors activate direct, inverted, and everted repeats," Annals of the New York Academy of Sciences, vol. 761, pp. 29-37, 1995.

[21] F. Rastinejad, T. Perlmann, R. M. Evans, and P. B. Sigler, "Structural determinants of nuclear receptor assembly on DNA direct repeats," Nature, vol. 375, no. 6528, pp. 203-211, 1995.

[22] Q. Zhao, S. A. Chasse, S. Devarakonda, M. L. Sierk, B. Ahvazi, and F. Rastinejad, "Structural basis of RXR-DNA interactions," Journal of Molecular Biology, vol. 296, no. 2, pp. 509-520, 2000.

[23] F. Rastinejad, T. Wagner, Q. Zhao, and S. Khorasanizadeh, "Structure of the RXR-RAR DNA-binding complex on the retinoic acid response element DR1," EMBO Journal, vol. 19, no. 5, pp. 1045-1054, 2000.

[24] J. D. Tugwood, I. Issemann, R. G. Anderson, K. R. Bundell, W. L. McPheat, and S. Green, "The mouse peroxisome proliferator activated receptor recognizes a response element in the $5^{\prime}$ flanking sequence of the rat acyl CoA oxidase gene," EMBO Journal, vol. 11, no. 2, pp. 433-439, 1992.

[25] V. Chandra, P. Huang, Y. Hamuro, et al., "Structure of the intact PPAR- $\gamma$-RXR- $\alpha$ nuclear receptor complex on DNA," Nature, vol. 456, no. 7220, pp. 350-356, 2008.

[26] S. Mader, P. Leroy, J.-Y. Chen, and P. Chambon, "Multiple parameters control the selectivity of nuclear receptors for their response elements. Selectivity and promiscuity in response element recognition by retinoic acid receptors and retinoid $\mathrm{X}$ receptors," Journal of Biological Chemistry, vol. 268, no. 1, pp. 591-600, 1993.

[27] B. M. Forman, J. Casanova, B. M. Raaka, J. Ghysdael, and H. H. Samuels, "Half-site spacing and orientation determines whether thyroid hormone and retinoic acid receptors and related factors bind to DNA response elements as monomers, homodimers, or heterodimers," Molecular Endocrinology, vol. 6, no. 3, pp. 429-442, 1992.

[28] A. M. Naar, J.-M. Boutin, S. M. Lipkin, et al., "The orientation and spacing of core DNA-binding motifs dictate selective transcriptional responses to three nuclear receptors," Cell, vol. 65, no. 7, pp. 1267-1279, 1991.

[29] R. Kurokawa, M. Soderstrom, A. Horlein, et al., "Polarityspecific activities of retinoic acid receptors determined by a co-repressor," Nature, vol. 377, no. 6548, pp. 451-454, 1995.

[30] R. Kurokawa, J. DiRenzo, and M. Boehm, "Regulation of retinoid signalling by receptor polarity and allosteric control of ligand binding," Nature, vol. 371, no. 6497, pp. 528-531, 1994.

[31] S. A. Kliewer, K. Umesono, D. J. Noonan, R. A. Heyman, and R. M. Evans, "Convergence of 9-cis retinoic acid and peroxisome proliferator signalling pathways through heterodimer formation of their receptors," Nature, vol. 358, no. 6389, pp. 771-774, 1992.

[32] D. J. Mangelsdorf, K. Umesono, S. A. Kliewer, U. Borgmeyer, E. S. Ong, and R. M. Evans, "A direct repeat in the cellular retinol-binding protein type II gene confers differential regulation by RXR and RAR," Cell, vol. 66, no. 3, pp. 555-561, 1991.

[33] H. Nakshatri and P. Bhat-Nakshatri, "Multiple parameters determine the specificity of transcriptional response by nuclear receptors HNF-4, ARP-1, PPAR, RAR and RXR through common response elements," Nucleic Acids Research, vol. 26, no. 10, pp. 2491-2499, 1998.

[34] A. IJpenberg, E. Jeannin, W. Wahli, and B. Desvergne, "Polarity and specific sequence requirements of peroxisome proliferator-activated receptor (PPAR)/retinoid X receptor heterodimer binding to DNA. A functional analysis of the malic enzyme gene PPAR response element," Journal of Biological Chemistry, vol. 272, no. 32, pp. 20108-20117, 1997.

[35] V. Vivat-Hannah, W. Bourguet, M. Gottardis, and H. Gronemeyer, "Separation of retinoid X receptor homo- and heterodimerization functions," Molecular and Cellular Biology, vol. 23, no. 21, pp. 7678-7688, 2003.

[36] W. Bourguet, M. Ruff, P. Chambon, H. Gronemeyer, and D. Moras, "Crystal structure of the ligand-binding domain of the human nuclear receptor RXR- $\alpha$," Nature, vol. 375, no. 6530, pp. 377-382, 1995.

[37] W. Bourguet, P. Germain, and H. Gronemeyer, "Nuclear receptor ligand-binding domains: three-dimensional structures, molecular interactions and pharmacological implications," Trends in Pharmacological Sciences, vol. 21, no. 10, pp. 381-388, 2000.

[38] R. T. Nolte, G. B. Wisely, S. Westin, et al., "Ligand binding and co-activator assembly of the peroxisome proliferator-activated receptor- $\gamma$," Nature, vol. 395, no. 6698, pp. 137-143, 1998.

[39] W. Bourguet, V. Vivat, J.-M. Wurtz, P. Chambon, H. Gronemeyer, and D. Moras, "Crystal structure of a heterodimeric complex of RAR and RXR ligand-binding domains," Molecular Cell, vol. 5, no. 2, pp. 289-298, 2000.

[40] V. Pogenberg, J.-F. Guichoul, V. Vivat-Hannah, et al., "Characterization of the interaction between retinoic acid receptor/retinoid X receptor (RAR/RXR) heterodimers and transcriptional coactivators through structural and fluorescence anisotropy studies," Journal of Biological Chemistry, vol. 280, no. 2, pp. 1625-1633, 2005.

[41] K. Suino, L. Peng, R. Reynolds, et al., "The nuclear xenobiotic receptor CAR: structural determinants of constitutive activation and heterodimerization," Molecular Cell, vol. 16, no. 6, pp. 893-905, 2004.

[42] R. X. Xu, M. H. Lambert, B. B. Wisely, et al., "A structural basis for constitutive activity in the human CAR/RXR $\alpha$ heterodimer," Molecular Cell, vol. 16, no. 6, pp. 919-928, 2004.

[43] M. C. Jaye, J. A. Krawiec, N. Campobasso, et al., "Discovery of substituted maleimides as liver $\mathrm{X}$ receptor agonists and determination of a ligand-bound crystal structure," Journal of Medicinal Chemistry, vol. 48, no. 17, pp. 5419-5422, 2005.

[44] S. Svensson, T. Östberg, M. Jacobsson, et al., "Crystal structure of the heterodimeric complex of LXR $\alpha$ and RXR $\beta$ ligandbinding domains in a fully agonistic conformation," $E M B O$ Journal, vol. 22, no. 18, pp. 4625-4633, 2003.

[45] R. T. Gampe Jr., V. G. Montana, M. H. Lambert, et al., "Asymmetry in the $\operatorname{PPAR} \gamma / \operatorname{RXR} \alpha$ crystal structure reveals the molecular basis of heterodimerization among nuclear receptors," Molecular Cell, vol. 5, pp. 545-555, 2000.

[46] H. E. Xu, M. H. Lambert, V. G. Montana, et al., "Structural determinants of ligand binding selectivity between the peroxisome proliferator-activated receptors," Proceedings of the National Academy of Sciences of the United States of America, vol. 98, no. 24, pp. 13919-13924, 2001. 
[47] C. D. Haffner, J. M. Lenhard, A. B. Miller, et al., "Structurebased design of potent retinoid X receptor $\alpha$ agonists," Journal of Medicinal Chemistry, vol. 47, no. 8, pp. 2010-2029, 2004.

[48] Z.-P. Chen, J. Iyer, W. Bourguet, et al., "Ligand- and DNAinduced dissociation of RXR tetramers," Journal of Molecular Biology, vol. 275, no. 1, pp. 55-65, 1998.

[49] D. Dong and N. Noy, "Heterodimer formation by retinoid $\mathrm{X}$ receptor: regulation by ligands and by the receptor's selfassociation properties," Biochemistry, vol. 37, no. 30, pp. 10691-10700, 1998.

[50] T. Ide, H. Shimano, T. Yoshikawa, et al., "Cross-talk between peroxisome proliferator-activated receptor (PPAR) $\alpha$ and liver $\mathrm{X}$ receptor (LXR) in nutritional regulation of fatty acid metabolism. II. LXRs suppress lipid degradation gene promoters through inhibition of PPAR signaling," Molecular Endocrinology, vol. 17, no. 7, pp. 1255-1267, 2003.

[51] T. Yoshikawa, T. Ide, H. Shimano, et al., "Cross-talk between peroxisome proliferator-activated receptor (PPAR) $\alpha$ and liver $X$ receptor (LXR) in nutritional regulation of fatty acid metabolism. I. PPARS suppress sterol regulatory element binding protein-1c promoter through inhibition of LXR signaling," Molecular Endocrinology, vol. 17, no. 7, pp. 12401254, 2003.

[52] K. S. Miyata, B. Zhang, S. L. Marcus, J. P. Capone, and R. A. Rachubinski, "Chicken ovalbumin upstream promoter transcription factor (COUP-TF) binds to a peroxisome proliferator-responsive element and antagonizes peroxisome proliferator-mediated signaling," Journal of Biological Chemistry, vol. 268, no. 26, pp. 19169-19172, 1993.

[53] K. Hashimoto, R. N. Cohen, M. Yamada, et al., "Cross-talk between thyroid hormone receptor and liver $\mathrm{X}$ receptor regulatory pathways is revealed in a thyroid hormone resistance mouse model," Journal of Biological Chemistry, vol. 281, no. 1, pp. 295-302, 2006.

[54] P. D. Thompson, J.-C. Hsieh, G. K. Whitfield, et al., "Vitamin $\mathrm{D}$ receptor displays DNA binding and transactivation as a heterodimer with the retinoid $\mathrm{X}$ receptor, but not with the thyroid hormone receptor," Journal of Cellular Biochemistry, vol. 75, no. 3, pp. 462-480, 1999.

[55] D. J. Waxman, "P450 gene induction by structurally diverse xenochemicals: central role of nuclear receptors CAR, PXR, and PPAR," Archives of Biochemistry and Biophysics, vol. 369, no. 1, pp. 11-23, 1999.

[56] X.-K. Zhang, G. Salbert, M.-O. Lee, and M. Pfahl, "Mutations that alter ligand-induced switches and dimerization activities in the retinoid X receptor," Molecular and Cellular Biology, vol. 14, no. 6, pp. 4311-4323, 1994.

[57] T. Perlmann, K. Umesono, P. N. Rangarajan, B. M. Forman, and R. M. Evans, "Two distinct dimerization interfaces differentially modulate target gene specificity of nuclear hormone receptors," Molecular Endocrinology, vol. 10, no. 8, pp. 958966, 1996.

[58] S.-K. Lee, B. Lee, and J. W. Lee, "Mutations in retinoid X receptor that impair heterodimerization with specific nuclear hormone receptor," Journal of Biological Chemistry, vol. 275, no. 43, pp. 33522-33526, 2000.

[59] S. Nakajima, J.-C. Hsieh, and P. N. MacDonald, "The Cterminal region of the vitamin $\mathrm{D}$ receptor is essential to form a complex with a receptor auxiliary factor required for high affinity binding to the vitamin D-responsive element," Molecular Endocrinology, vol. 8, no. 2, pp. 159-172, 1994.

[60] H. M. Sucov, E. Dyson, C. L. Gumeringer, J. Price, K. R. Chien, and R. M. Evans, "RXR $\alpha$ mutant mice establish a genetic basis for vitamin A signaling in heart morphogenesis," Genes and Development, vol. 8, no. 9, pp. 1007-1018, 1994.

[61] J. Chen, S. W. Kubalak, and K. R. Chien, "Ventricular musclerestricted targeting of the $\operatorname{RXR} \alpha$ gene reveals a non-cellautonomous requirement in cardiac chamber morphogenesis," Development, vol. 125, no. 10, pp. 1943-1949, 1998.

[62] Y. Wu, X. Zhang, F. Bardag-Gorce, et al., "Retinoid X receptor $\alpha$ regulates glutathione homeostasis and xenobiotic detoxification processes in mouse liver," Molecular Pharmacology, vol. 65, no. 3, pp. 550-557, 2004.

[63] T. Imai, M. Jiang, P. Kastner, P. Chambon, and D. Metzger, "Selective ablation of retinoid X receptor $\alpha$ in hepatocytes impairs their lifespan and regenerative capacity," Proceedings of the National Academy of Sciences of the United States of America, vol. 98, no. 8, pp. 4581-4586, 2001.

[64] M. Li, A. K. Indra, X. Warot, et al., "Skin abnormalities generated by temporally controlled RXR $\alpha$ mutations in mouse epidermis," Nature, vol. 407, no. 6804, pp. 633-636, 2000.

[65] B. Chapellier, M. Mark, N. Messaddeq, et al., "Physiological and retinoid-induced proliferations of epidermis basal keratinocytes are differently controlled," EMBO Journal, vol. 21, no. 13, pp. 3402-3413, 2002.

[66] J. Huang, W. C. Powell, A. C. Khodavirdi, et al., "Prostatic intraepithelial neoplasia in mice with conditional disruption of the retinoid X receptor $\alpha$ allele in the prostate epithelium," Cancer Research, vol. 62, no. 16, pp. 4812-4819, 2002.

[67] Y. Barak, M. C. Nelson, E. S. Ong, et al., "PPAR $\gamma$ is required for placental, cardiac, and adipose tissue development," Molecular Cell, vol. 4, no. 4, pp. 585-595, 1999.

[68] S. M. Rangwala and M. A. Lazar, "Peroxisome proliferatoractivated receptor $\gamma$ in diabetes and metabolism," Trends in Pharmacological Sciences, vol. 25, no. 6, pp. 331-336, 2004.

[69] N. Kubota, Y. Terauchi, H. Miki, et al., "PPAR $\gamma$ mediates high-fat diet-induced adipocyte hypertrophy and insulin resistance," Molecular Cell, vol. 4, no. 4, pp. 597-609, 1999.

[70] P. Chambon, "The retinoid signaling pathway: molecular and genetic analyses," Seminars in Cell Biology, vol. 5, no. 2, pp. 115-125, 1994.

[71] M. Mark, N. B. Ghyselinck, O. Wendling, et al., "A genetic dissection of the retinoid signalling pathway in the mouse," Proceedings of the Nutrition Society, vol. 58, no. 2, pp. 609-613, 1999.

[72] E. Hondares, O. Mora, P. Yubero, et al., "Thiazolidinediones and rexinoids induce peroxisome proliferator-activated receptor-coactivator (PGC)-1 $\alpha$ gene transcription: an autoregulatory loop controls PGC- $1 \alpha$ expression in adipocytes via peroxisome proliferator-activated receptor- $\gamma$ coactivation," Endocrinology, vol. 147, no. 6, pp. 2829-2838, 2006.

[73] T. Teruel, J. C. Clapham, and S. A. Smith, "PPAR $\gamma$ activation by Wy 14643 induces transactivation of the Rat UCP-1 promoter without increasing UCP-1 mRNA levels and attenuates PPAR $\gamma$-mediated increases in UCP-1 mRNA levels induced by rosiglitazone in fetal rat brown adipocytes," Biochemical and Biophysical Research Communications, vol. 264, no. 2, pp. 311315, 1999.

[74] J. Berger, M. D. Leibowitz, T. W. Doebber, et al., "Novel peroxisome proliferator-activated receptor (PPAR) $\gamma$ and PPAR $\delta$ ligands produce distinct biological effects," Journal of Biological Chemistry, vol. 274, no. 10, pp. 6718-6725, 1999.

[75] J. E. Cobb, S. G. Blanchard, E. G. Boswell, et al., "N(2-benzoylphenyl)-L-tyrosine PPAR $\gamma$ agonists. 3. Structureactivity relationship and optimization of the $\mathrm{N}$-aryl substituent," Journal of Medicinal Chemistry, vol. 41, no. 25, pp. 5055-5069, 1998. 
[76] H. M. Wright, C. B. Clish, T. Mikami, et al., "A synthetic antagonist for the peroxisome proliferator-activated receptor $\gamma$ inhibits adipocyte differentiation," Journal of Biological Chemistry, vol. 275, no. 3, pp. 1873-1877, 2000.

[77] R. Mukherjee, P. A. Hoener, L. Jow, et al., "A selective peroxisome proliferator-activated receptor- $\gamma(\operatorname{PPAR} \gamma)$ modulator blocks adipocyte differentiation but stimulates glucose uptake in 3T3-L1 adipocytes," Molecular Endocrinology, vol. 14, no. 9, pp. 1425-1433, 2000.

[78] T.-C. He, T. A. Chan, B. Vogelstein, and K. W. Kinzler, "PPAR $\delta$ is an APC-regulated target of nonsteroidal anti-inflammatory drugs," Cell, vol. 99, no. 3, pp. 335-345, 1999.

[79] C. L. Chaffer, D. M. Thomas, E. W. Thompson, and E. D. Williams, "PPAR $\gamma$-independent induction of growth arrest and apoptosis in prostate and bladder carcinoma," BMC Cancer, vol. 6, article 53, 2006.

[80] C.-C. Yang, C.-Y. Ku, S. Wei, et al., "Peroxisome proliferatoractivated receptor $\gamma$-independent repression of prostatespecific antigen expression by thiazolidinediones in prostate cancer cells," Molecular Pharmacology, vol. 69, no. 5, pp. 15641570, 2006.

[81] S. Aggarwal, S.-W. Kim, K. Cheon, F. H. Tabassam, J.-H. Yoon, and J. S. Koo, "Nonclassical action of retinoic acid on the activation of the cAMP response element-binding protein in normal human bronchial epithelial cells," Molecular Biology of the Cell, vol. 17, no. 2, pp. 566-575, 2006.

[82] L. S. Chan and R. A. Wells, "Manipulation of reciprocal salt bridges at the heterodimerization interface alters the dimerization properties of mouse $\operatorname{RXR} \alpha$ and $\operatorname{PPAR} \gamma 1$," Biochemical and Biophysical Research Communications, vol. 358, no. 4, pp. 1080-1085, 2007. 


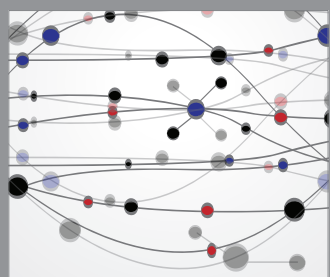

The Scientific World Journal
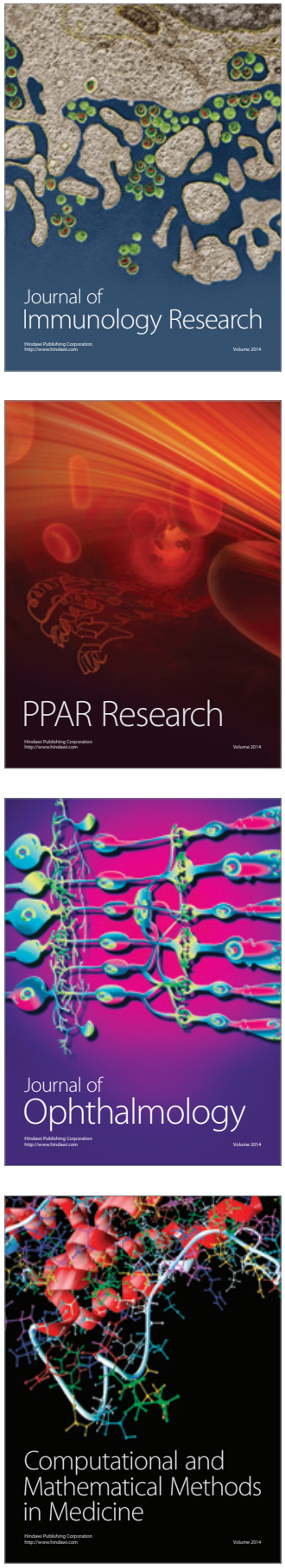

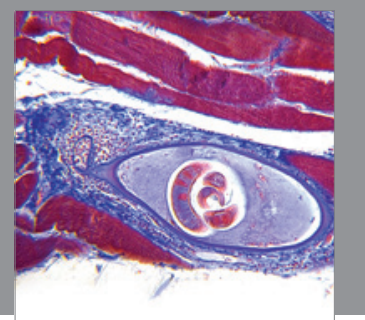

Gastroenterology

Research and Practice
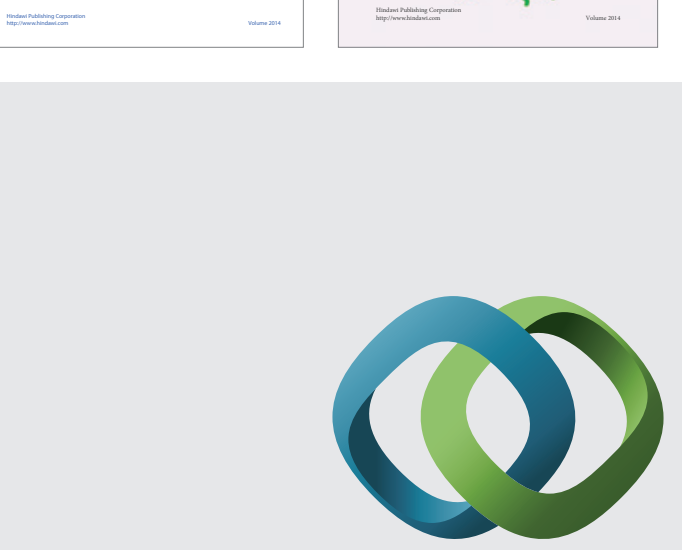

\section{Hindawi}

Submit your manuscripts at

http://www.hindawi.com
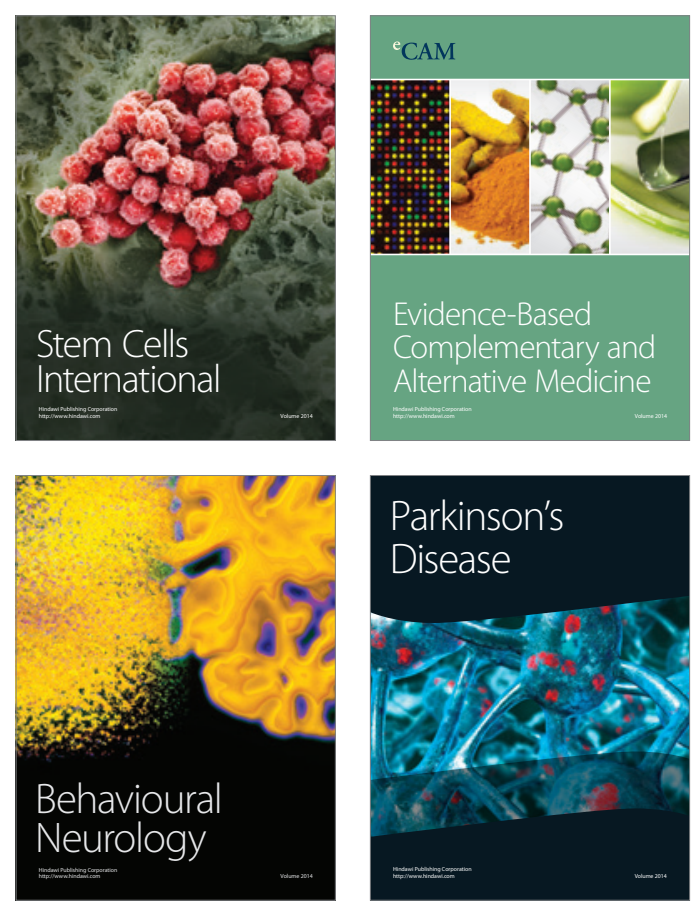

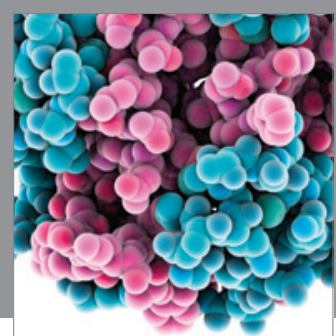

Journal of
Diabetes Research

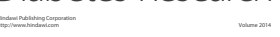

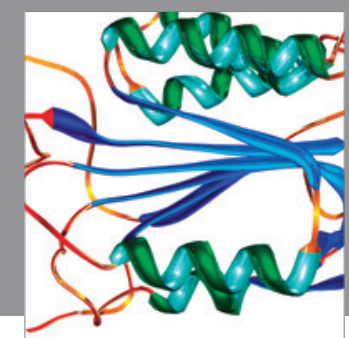

Disease Markers
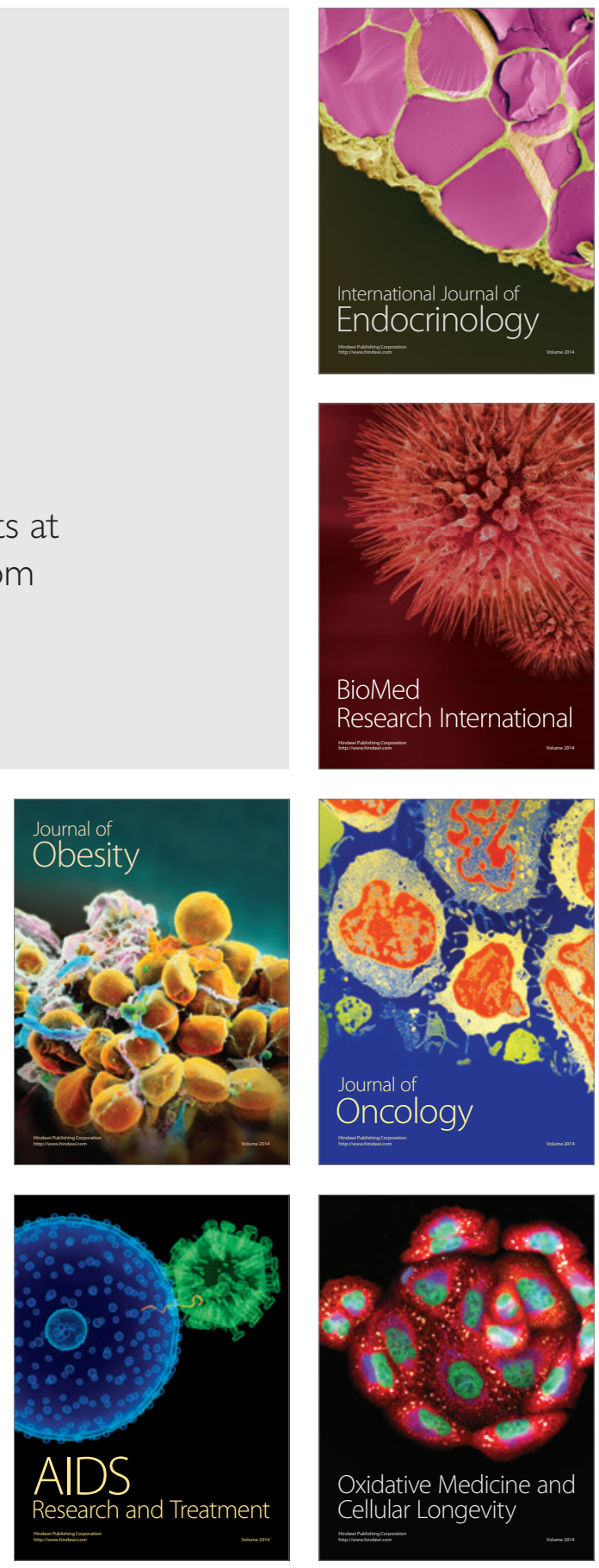